\title{
Traditional medicine, Sobokchukeo-Tang, modulates the inflammatory response in adipocytes and macrophages
}

\author{
HOYOUNG LEE ${ }^{1,2}$, EUN HYOUNG SHIM ${ }^{1}$, MYEONG SOO LEE ${ }^{3 *}$ and CHANG-SEON MYUNG ${ }^{2 *}$ \\ ${ }^{1}$ KM Fundamental Research Division, Korea Institute of Oriental Medicine, Daejeon 34054; \\ ${ }^{2}$ Department of Pharmacology, Chungnam National University College of Pharmacy, Daejeon 34134; \\ ${ }^{3}$ Clinical Research Division, Korea Institute of Oriental Medicine, Daejeon 34054, Republic of Korea
}

Received November 19, 2015; Accepted November 2, 2016

DOI: $10.3892 / \mathrm{mmr} .2016 .6005$

\begin{abstract}
Sobokchukeo-Tang (ST) is a well-known formula that is used for treating primary dysmenorrhea caused by blood stasis syndrome (BSS) in Korea and China. The current study investigated the anti-inflammatory and anti-adipogenesis effects of ST on adipocytes and macrophages. The anti-inflammatory efficacy of ST was evaluated in RAW 264.7 cells and differentiated THP-1 cells. To induce inflammation, the cells were treated with lipopolysaccharide (LPS; $1 \mu \mathrm{g} / \mathrm{ml}$ ). Following the induction of inflammation, the levels of proinflammatory cytokines, interleukin-6 (IL-6) and tumor necrosis factor- $\alpha$ (TNF- $\alpha$ ) in the cell supernatant were detected using enzyme-linked immunosorbent assay. 3T3-L1 preadipocytes differentiated into adipocytes in response to insulin, isobutyl-1-methylxanthine and dexamethasone (MDI). To confirm the anti-adipogenesis efficacy of ST, we investigated Oil Red O staining was performed, triglyceride (TG) and leptin secretion were measured, and the protein expression of lipid metabolism-associated factors was determined. ST significantly inhibited TNF- $\alpha$ and IL-6 production in the LPS-treated RAW 264.7 cells compared with LPS stimulation alone. In addition, the concentrations of IL- 6 and TNF- $\alpha$ were significantly inhibited by ST in LPS-treated THP-1 cells. Lipid accumulation was reduced by ST, similarly to the positive control treatment, SB203580. In the ST-treated group, the TG and leptin concentrations were
\end{abstract}

Correspondence to: Dr Myeong Soo Lee, Clinical Research Division, Korea Institute of Oriental Medicine, 1672 Yuseong-daero, Yuseong-gu, Daejeon 34054, Republic of Korea

E-mail: drmslee@gmail.com

Professor Chang-Seon Myung, Department of Pharmacology, Chungnam National University College of Pharmacy, 99 Daehak-Ro, Yuseong-gu, Daejeon 34134, Republic of Korea

E-mail:cm8r@cnu.ac.kr

*Contributed equally

Key words: Sobokchukeo-Tang, anti-inflammatory, anti-adipogenesis, blood stasis syndrome inhibited by up to 50 and $83 \%$, respectively, compared with MDI induction only. The ST-treated group reduced the protein expression of peroxisome proliferator-activated receptor- $\gamma$ and CCAAT/enhancer-binding protein $\alpha$ compared with MDI induction only. The results of the present study demonstrated that ST exerts anti-inflammatory effects on LPS-treated mouse and human macrophage cell lines. ST inhibited adipogenesis in MDI-induced 3T3-L1 adipocytes, as indicated by the significant reduction in TG and leptin concentrations without cytotoxicity. Thus, ST may be useful as a therapeutic agent for preventing lipid-associated diseases, including obesity and atherosclerosis.

\section{Introduction}

Blood stasis syndrome (BSS) is an interesting research area in studies of traditional Asian and Western medicine (1) focused on vascular disease. In Korean Traditional Medicine (KTM), BSS is considered to be caused by blood circulation and Qi circulatory disturbances, which are the result of accidents, surgery and stress (2). Clinically, BSS is characterized by pain, bleeding and coagulation, in the vasculature and the muscles. It is diagnosed based on increased viscosity of the blood, red blood cell (RBC) deformability, and the acceleration of RBC maturation, platelet aggregation and microcirculatory dysfunction (3). Recently, various studies have reported that BSS is important in metabolic diseases (MDs) (4), including obesity, atherosclerosis and cardiovascular disease (5). Previous studies have demonstrated that MDs are closely associated with inflammation in vascular diseases $(6,7)$.

Sobokchukeo-Tang (ST) is a well-known formula that is used for treating primary dysmenorrhea caused by BSS in Korea and China. ST is used to treat BSS, including uterine myoma, primary dysmenorrhea and chronic pelvic inflammation (8). Other reports have described the efficacy of ST for treating vascular disorders and pain (9), endometriosis (10), cancer (11) and menstrual irregularities in vivo (12).

It is established that the levels of tumor necrosis factor- $\alpha$ (TNF- $\alpha$ ) and interleukin-6 (IL-6) are increased in MD patients (13). Lipid diseases, including obesity and atherosclerosis, are associated with the elevated concentration of inflammatory markers, including $\mathrm{C}$-reactive protein and 
proinflammatory cytokines, including interleukin-1 $\beta$ (IL-1 $\beta$ ), IL-6 and TNF- $\alpha$ (14-16).

Peroxisome proliferator-activated receptors (PPARs) are ligand-dependent transcription factors that regulate lipid and glucose metabolism (17). PPARs predominantly include three subtypes; $\delta, \beta$ and $\gamma$. The major role of PPAR $-\gamma$ in adipocytes is the regulation of adipogenesis and lipid homeostasis, whereas PPAR- $\delta$ is expressed in hepatocytes, enterocytes and the renal proximal tubule cells of the kidney. Despite research into PPAR- $\alpha$ and PPAR- $\gamma$, the molecular function of PPAR- $\beta$ remains unclear. However, PPAR- $\beta$ is expressed in many regions of tissues and cells, with relatively high levels present in the brain, adipose tissue and skin (18). The CCAAT/enhancer-binding protein (C/EBP) family also serves an important role in modulating adipocytes (19). These adipogenic transcriptional factors modulate lipid production in the immune system.

The present study observed the anti-inflammatory effects of ST extracts on macrophage cell lines. The anti-adipogenesis efficacy of ST on mouse fibroblast cell lines was also investigated. The results demonstrated that ST modulated adipokine expression under inflammatory conditions.

\section{Materials and methods}

Preparation of the herbal formula. Each of the 10 herbal components of ST were mixed as listed in Table I. All herbal components were purchased from Omniherb (Deagu, Korea) in 2012. The origins of each herb were confirmed by Dr Jun-Kyung Lee of Hyemin Dispensary of Oriental Medicine (Jeonju, Korea). A voucher specimen (BS-6) was deposited at the KM fundamental Research Division, Korea Institute of Oriental Medicine (Daejeon, Korea). The extracts were prepared in our laboratory from a mixture of chopped crude herbs. Extraction was performed using distilled water at $100^{\circ} \mathrm{C}$ for $3 \mathrm{~h}$ by reflux extraction, using the extractor COSMOS-660 (Kyungseo Machine Co., Incheon, Korea). The solution was filtered through filter paper. The extract was freeze-dried to create a powder (extraction yield, 13.04\%). The prepared powder was stored at $-70^{\circ} \mathrm{C}$.

High performance liquid chromatography (HPLC) analysis. The lyophilized extract (10 mg) was dissolved in $70 \%$ methanol $(5 \mathrm{ml})$ and then filtered through a $0.2 \mu \mathrm{m}$ membrane filter (Woongki Science Co., Ltd., Seoul, Korea) before being injected into HPLC for component analysis. The purity of the ten standard compounds was $\geq 98.0 \%$ using HPLC analysis. The HPLC-grade solvents, methanol, acetonitrile and water were obtained from J.T. Baker (Phillipsburg, NJ, USA). Trifluoroacetic acid (analytical reagent grade) and the standards were procured from Sigma-Aldrich (Merck Millipore, Darmstadt, Germany).

The HPLC system consisted of a Waters Alliance 2695 system coupled with a 2998 photodiode array detector (Waters Corporation, Mitford, MA, USA). Data processing was performed with Empower software, version 3 (Waters Corporation). The 10 components in ST were separated using a Luna $5 \mu \mathrm{m} \mathrm{C18} \mathrm{100A} \mathrm{column}(4.6 \times 250 \mathrm{~mm}, 5 \mu \mathrm{m}$ particle size, no. 00G-4252-E0; Phenomenex, Inc., Torrance, CA, USA). The monitoring was performed at $230 \mathrm{~nm}$ for three compounds
(1, albiflorin; 2, paeoniflorin; and 3, benzoic acid), $280 \mathrm{~nm}$ for five compounds (4, gallic acid; 5, coumarin; 6, cinnamic acid; 7, cinnamic aldehyde; and 8,6-gingerol) and $320 \mathrm{~nm}$ for two compounds [9, nodakenin; and 10, ferulic acid (10)]. The mobile phases consisted of water with $0.1 \%(\mathrm{v} / \mathrm{v})$ trifluoroacetic acid (solvent $\mathrm{A}$ ) and acetonitrile (solvent $\mathrm{B}$ ) at a flow rate of $1.0 \mathrm{ml} / \mathrm{min}$. The gradient conditions changed as presented in Table II. The injection volume was $10 \mu 1$.

Cell culture and cytotoxicity. The RAW 264.7 murine macrophage cell line, the 3T3-L1 mouse embryonic fibroblast cell line and the THP-1 human acute monocytic leukemia cell line were obtained from the American Type Culture Collection (ATCC; Manassas, VA, USA). The RAW 264.7 [5.5\% fetal bovine serum (FBS, Gibco; Thermo Fisher Scientific, Inc., Waltham, MA, USA) and $1 \%$ penicillin/streptomycin $(\mathrm{P} / \mathrm{S})]$ and 3T3-L1 (10\% calf serum and $1 \% \mathrm{P} / \mathrm{S})$ cells were cultured in Dulbecco's modified Eagle's medium (DMEM; Gibco; Thermo Fisher Scientific, Inc.). The THP-1 cells were cultured in RPMI-1640 medium (Gibco; Thermo Fisher Scientific, Inc.; $10 \% \mathrm{FBS}, 1 \% \mathrm{P} \& \mathrm{~S})$. The culture flask was maintained at $37^{\circ} \mathrm{C}$ in a humidified atmosphere consisting of $5 \% \mathrm{CO}_{2}$ and $95 \%$ air.

The cell cytotoxicity was detected by using Cell Counting Kit-8 (CCK-8; Dojindo Molecular Technologies, Inc., Kumamoto, Japan). Briefly, the RAW 264.7, 3T3-L1 and THP-1 cells were seeded at $3 \times 10^{3}, 8 \times 10^{2}$ and $1 \times 10^{4}$ cells/well in 96-well plates. After incubation overnight, the cells were treated with $0-1,000 \mu \mathrm{g} / \mathrm{ml} \mathrm{ST}$ for $24 \mathrm{~h}$. CCK-8 solution $(10 \mu \mathrm{l})$ was added to each well. After $4 \mathrm{~h}$, the absorbance was measured at $450 \mathrm{~nm}$ using a Benchmark Plus microplate reader (Bio-Rad Laboratories, Inc., Hercules, CA, USA), and the percentages of the control (without ST) were calculated.

Anti-inflammatory activity. To confirm the levels of cytokines in the RAW 264.7 cells, the cells were cultured with $5 \times 10^{4}$ cells per well in 48 -well plates with lipopolysaccharide (LPS; Escherichia coli 0111:B4; Sigma-Aldrich, Merck Millipore; $1 \mu \mathrm{g} / \mathrm{ml}$ ) for $24 \mathrm{~h}$ to induce inflammation. The cells were treated with ST extract $(62.5-500 \mu \mathrm{g} / \mathrm{ml})$. The IL-6 (cat. no. DY406) and TNF- $\alpha$ (cat. no. DY410) concentration in the supernatant was analyzed using ELISA (R\&D Systems, Inc., Minneapolis, MN, USA).

THP-1 cells were cultured at $1 \times 10^{6}$ cells/well in 6 -well plates in the presence of phorbol 12-myristate 13-acetate (20 ng/ml; Sigma-Aldrich; Merck Millipore) for $24 \mathrm{~h}$ to induce differentiation into macrophage-like cells. Differentiated cells were then incubated with serum-free medium for 1 day at $37^{\circ} \mathrm{C}$ and $5 \% \mathrm{CO}_{2}$. Cells were treated with LPS $(1 \mu \mathrm{g} / \mathrm{ml})$ in RPMI medium $(10 \% \mathrm{FBS}$ and $1 \% \mathrm{P} / \mathrm{S})$ in the presence or absence of ST extracts $(62.5-500 \mu \mathrm{g} / \mathrm{ml})$. The cells were incubated for $24 \mathrm{~h}$, then the supernatant was taken to measure the concentration of proinflammatory cytokines [IL-1 $\beta$ (cat. no. KHC0014), IL-6 (cat. no. KHC0061C) and TNF- $\alpha$ (cat. no. KHC3014C); Invitrogen; Thermo Fisher Scientific, Inc.].

3T3-L1 cell culture and differentiation. To induce adipocyte differentiation, the 3T3-L1 cells were cultures in 6-well plates at $3 \times 10^{5}$ cells/well to confluence. After 2 days, the cells were treated with a differentiation mixture containing $1 \mu \mathrm{M}$ dexamethasone, $5 \mathrm{mM} 3$-isobutyl-1-methylxanthine and $1 \mu \mathrm{g} / \mathrm{ml}$ 
Table I. Composition of Sobokchukeo-Tang.

Name of herbs

Binomial name

Amount (g)

Foeniculi Fructus

Zingiberis Rhizoma

Foeniculum vulgare Mill.

4.0

Carthami Flos

Zingiber officinale Roscoe

0.8

Myrrha

Corydalis ternata Nakai

4.0

Angelicae Sinens Radix

Commiphora molmol Engler

4.0

Cnidii Rhizoma

Angelica gigas $N$.

12.0

Cinnammomi Cortex

Cnidium officinale Makino

4.0

Cinnamomum loureirii Nees

4.0

Paeoniae Rubra Radix

Paeonia obovata Maxim.

8.0

Typhae Pollen

Typha angustifolia L.

12.0

Trogopterori Faeces

Trogopterus xanthipes

8.0

Yield following lyophilization is $13.04 \%$.

Table II. Composition of mobile phase for chromatographic separation.

\begin{tabular}{lcc}
\hline Time (min) & Solvent A $(\%)^{\mathrm{a}}$ & Solvent B $(\%)^{\mathrm{b}}$ \\
\hline 0 & 95 & 5 \\
30 & 40 & 60 \\
40 & 0 & 100 \\
45 & 0 & 100 \\
50 & 95 & 5 \\
60 & 95 & 5 \\
\hline
\end{tabular}

${ }^{\mathrm{a}} 0.1 \%(\mathrm{v} / \mathrm{v})$ trifluoroacetic acid in water. ${ }^{\mathrm{b}}$ Acetonitrile.

insulin (Sigma-Aldrich; Merck Millipore) in DMEM with $10 \%$ FBS (MDI) to induce the preadipocytes to differentiate. After 2 days, the medium was replaced with DMEM with $10 \%$ FBS and $1 \mu \mathrm{M}$ insulin. Cultures were incubated for 2 days, after which the culture medium was replaced again with DMEM (10\% FBS) and repeated at 2 day intervals until day 7. SB203580, a p38 mitogen-activated protein kinase (MAPK) inhibitor (Cell Signaling Technologies, Inc., Danvers, MA, USA) was used as the positive control. The triglyceride (TG; BioAssay Systems, Hayward, CA, USA; cat. no. ETGA-200) was detected by colorimetric method in the cell lysates at $570 \mathrm{~nm}$ using a microplate reader (Benchmark Plus; Bio-Rad Laboratories, Inc.). The leptin (R\&D Systems, Inc.; cat. no. MOB00) concentrations were measured by ELISA in supernatant at $450 \mathrm{~nm}$ using a microplate reader.

Oil Red $O(O R O)$ staining. MDI-induced differentiated 3T3-L1 cells were treated with ST at concentrations of 62.5 , 125,250 and $500 \mu \mathrm{g} / \mathrm{ml}$. The fat droplets were visualized using ORO staining. The cells were fixed with $10 \%$ formalin for $1 \mathrm{~h}$, washed with $60 \%$ isopropanol, and dried. Then, the cells were stained with $0.5 \%$ ORO solution in $60 \%$ isopropanol for $10 \mathrm{~min}$ and then washed four times with distilled water. The images of the stained cells were acquired using an inverted contrast phase microscope (Olympus Corporation, Tokyo,
Japan). To detect the absorbance of the sample, the stained cells were dissolved in DMSO and absorbance was measured at $570 \mathrm{~nm}$ by a microplate reader.

Anti-adipogenesis activity. The TG and leptin production was measured on day 7 after differentiation. The cells were washed three times with PBS and scraped in $500 \mu 15 \%$ Triton $\mathrm{X}-100$. The cell lysate was centrifuge at $848 \mathrm{x} \mathrm{g}$ for $3 \mathrm{~min}$ at $4^{\circ} \mathrm{C}$ to remove the fat layers. The supernatant was assayed for TG production, according to the manufacturer's protocol (BioAssay Systems; cat. no. ETGA-200). The supernatant in the differentiated 3T3-L1 cells treated with ST were used to determine the leptin concentration according to the manufacturer's protocol (R\&D Systems, Inc.; cat. no. MOB00).

Protein expression. Cells were treated with ST (62.5, 125, 250 and $500 \mu \mathrm{g} / \mathrm{ml}$ ) for 5 days and then washed twice with ice-cold PBS. The cell lysates were prepared with radioimmunoprecipitation cell lysis buffer (GenDEPOT, Barker, TX, USA). The lysates were centrifuged at $15,928 \mathrm{x} \mathrm{g}$ for $15 \mathrm{~min}$ at $4^{\circ} \mathrm{C}$. The concentration of protein was measured using the Bicinchoninic Acid Protein Assay kit (Thermo Fisher Scientific, Inc.). A total of $30 \mu \mathrm{g}$ of each protein was separated by electrophoresis using 4-20\% Criterion $^{\mathrm{TM}}$ TGX $^{\mathrm{TM}}$ precast gels (Bio-Rad Laboratories, Inc.) and transferred onto polyvinylidene fluoride membranes (GE Healthcare Life Sciences, Chalfont, UK). The membranes were blocked with $5 \%$ skim milk and incubated with primary antibodies (1:1,000 dilutions; $\beta$-actin (cat. no. sc-81178), PPAR- $\gamma$ (cat. no. sc-7273), C/EBP $\alpha$ (cat. no. sc-61); Santa Cruz Biotechnology, Inc., Dallas, Texas. USA) overnight at $4^{\circ} \mathrm{C}$. The next day, the membranes were incubated with goat anti-rabbit secondary antibodies (1:5,000; cat. no. 170-6515; Bio-Rad Laboratories, Inc.) for $1 \mathrm{~h}$ at room temperature, and immunoreactive proteins were detected using an enhanced chemiluminescence assay kit (Thermo Fisher Scientific, Inc.). Bands were detected using a ChemiDoc ${ }^{\mathrm{TM}}$ XRS + image analyzer (Bio-Rad Laboratories, Inc.).

Statistical analysis. Data are presented as the mean \pm standard error and were analyzed by analysis of variance and the Bonferroni multiple comparison method using Systat 13.0 

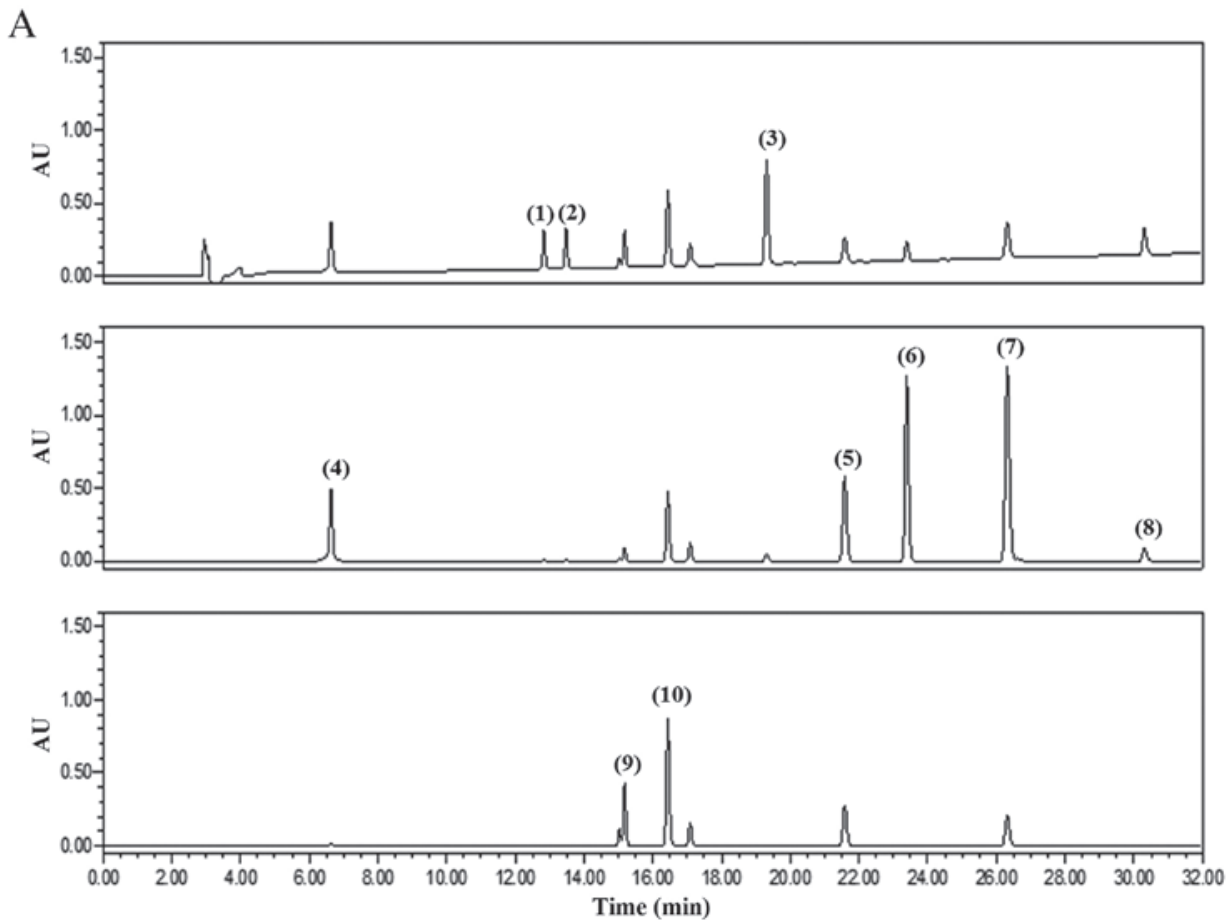

B
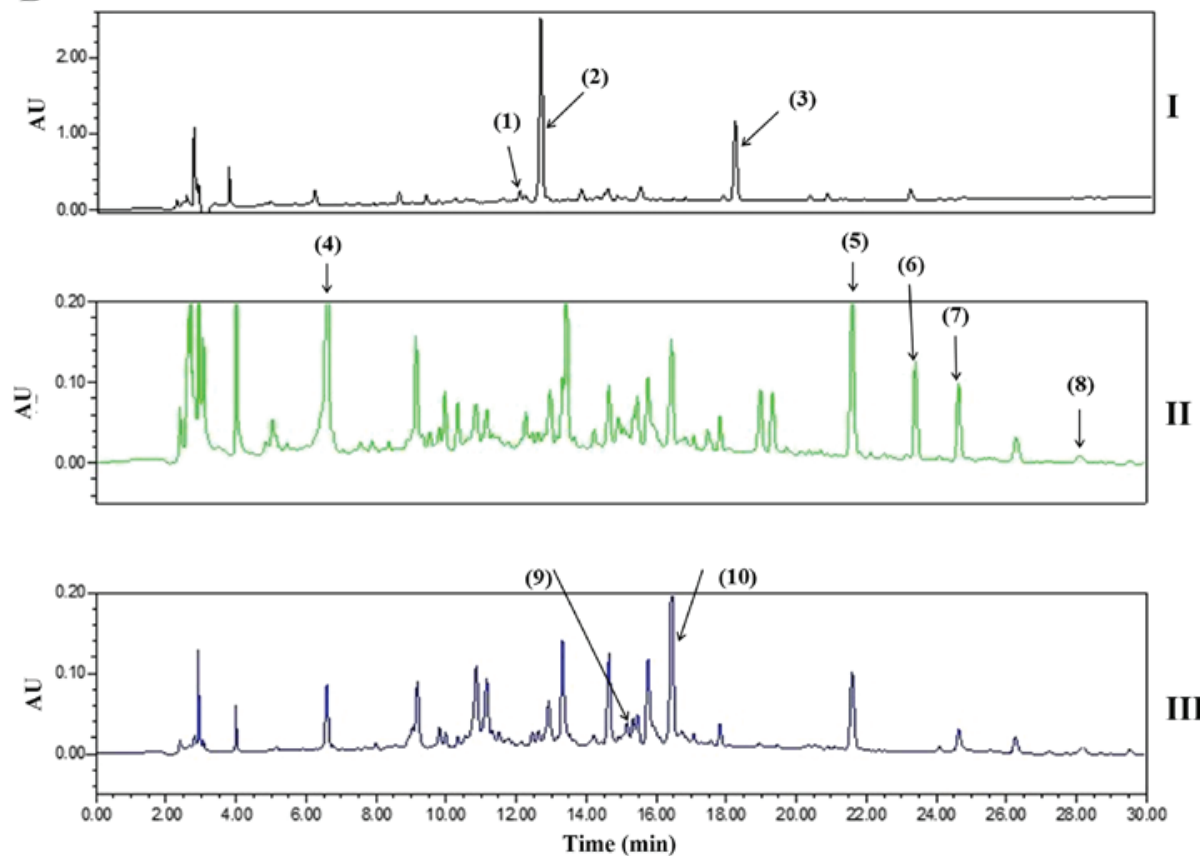

Figure 1. High performance liquid chromatography chromatogram of (A) standard mixture and (B) Sobokchukeo-Tang. I, 230 nm; II, 280 nm; and III, $330 \mathrm{~nm}$. (1) Alboflorin, (2) peoniflorin, (3) benzoic acid, (4) gallic acid, (5) coumarin, (6) cinnamic acid, (7) cinnamic aldehyde, (8) 6-gingerol, (9) nodakenin (10) and ferulic acid. AU, absorbance unit.

(Systat Software Inc., San Jose, CA USA). P<0.05 was considered to indicate a statistically significant difference.

\section{Results}

HPLC analysis. Satisfactory results were obtained using mobile phases consisting of $1.0 \%(\mathrm{v} / \mathrm{v})$ trifluoroacetic acid (solvent A) and acetonitrile with $1.0 \%$ (v/v) trifluoroacetic acid (solvent B). Quantitation was achieved using photodiode array detection in the region $200-400 \mathrm{~nm}$ based on the retention times and UV spectra compared with the standards. The UV absorbance was recorded at $230 \mathrm{~nm}$ for three compounds, $280 \mathrm{~nm}$ for five compounds and $320 \mathrm{~nm}$ for two compounds. The retention times of compounds $1-10$ were $12.80,13.44$, $19.32,6.60,21.60,23.41,24.64,30.30,15.17$ and $16.44 \mathrm{~min}$, respectively (Fig. 1A). Fig. 1B presents the chromatograms of the ST extract solutions.

Anti-inflammatory activity. There was no cytotoxicity up to $1,000 \mu \mathrm{g} / \mathrm{ml} \mathrm{ST}$ (data not shown). The cytokine concentrations 

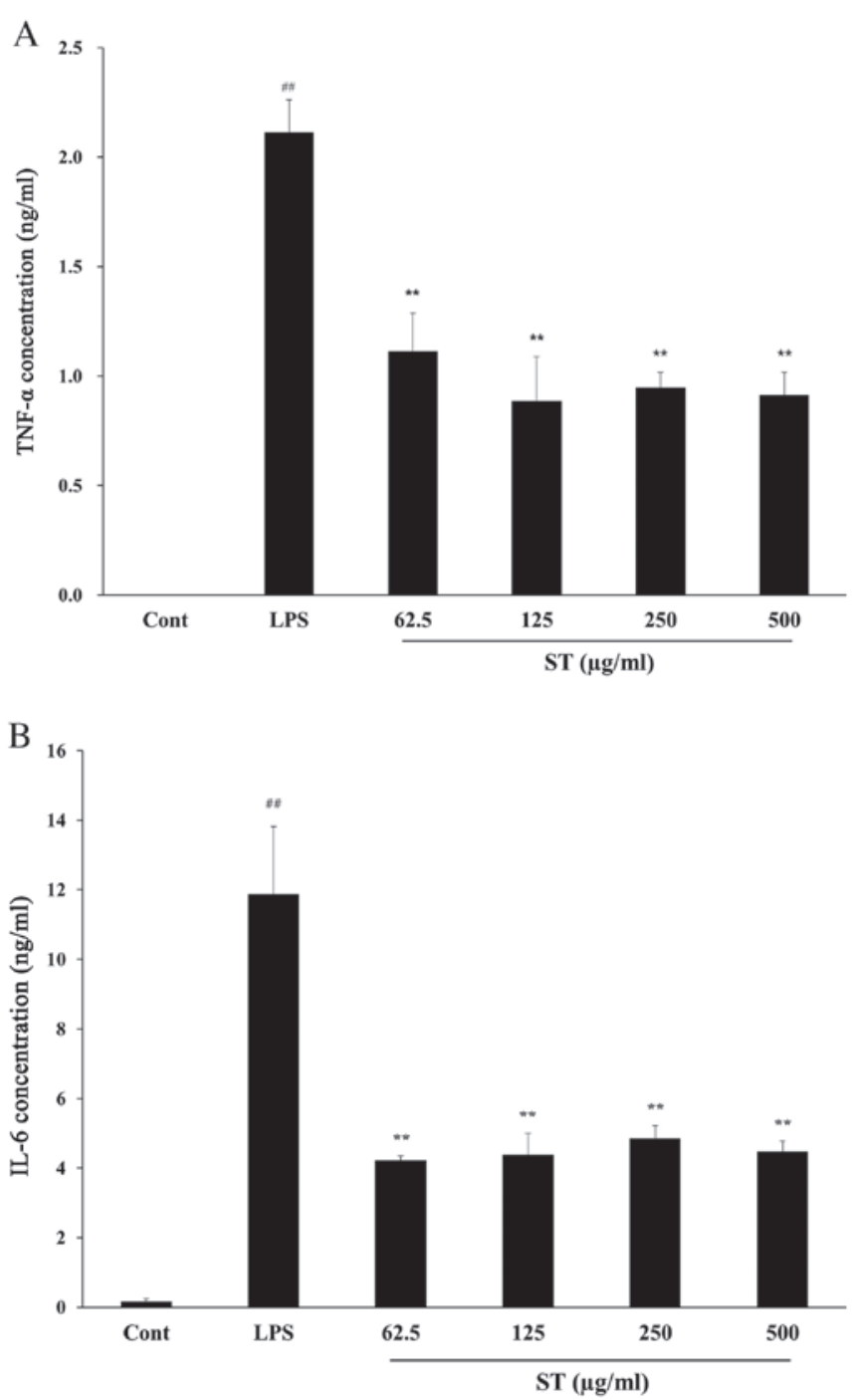

Figure 2. Inhibition of TNF- $\alpha$ and IL-6 expression by ST in LPS-stimulated RAW 264.7 cells. Cells were treated with various concentrations of ST with LPS $(1 \mu \mathrm{g} / \mathrm{ml})$ for $24 \mathrm{~h}$. (A) TNF- $\alpha$ and (B) IL-6 production was inhibited by ST in LPS-stimulated RAW 264.7 cells compared with LPS only-treated cells. The data are presented as the mean \pm standard error of three independent experiments. ${ }^{\# \#} \mathrm{P}<0.01$ vs. cont; ${ }^{* *} \mathrm{P}<0.01$ vs. LPS. TNF- $\alpha$, tumor necrosis factor- $\alpha$; Cont, control; LPS, lipopolysaccharide; ST, Sobokchukeo-Tang; IL-6, interleukin-6.

were detected in the supernatants of LPS-treated RAW 264.7 cells and THP-1 cells. The inflammatory efficacy was examined using mouse and human cell lines.

ST significantly inhibited the production of TNF- $\alpha$ by up to $57 \%$ in LPS-treated RAW 264.7 mouse cells compared with cells treated with LPS only (P<0.01; Fig. 2A). The IL-6 concentration in the LPS-treated group $(11.87 \pm 1.95 \mathrm{ng} / \mathrm{ml})$ exhibited a significant increase of $\sim 72$-fold compared with the control group $(0.16 \pm 0.076 \mathrm{ng} / \mathrm{ml} ; \mathrm{P}<0.0001)$ and IL-6 was significantly reduced by ST $(500 \mu \mathrm{g} / \mathrm{ml})$ by $59-65 \%$ compared with LPS treatment ( $\mathrm{P}=0.008$; Fig. $2 \mathrm{~B})$.

Cytokine levels were also measured in human THP-1 cells. The LPS-treated group exhibited significantly increased concentrations of IL-1 $\beta(12.79 \pm 1.61 \mathrm{ng} / \mathrm{ml}$; $\mathrm{P}<0.0001)$, IL-6 $(8.58 \pm 1.21 \mathrm{ng} / \mathrm{ml} ; \mathrm{P}<0.0001)$ and TNF- $\alpha$ $(69.95 \pm 0.75 \mathrm{ng} / \mathrm{ml} ; \mathrm{P}<0.0001)$ compared with the control. The ST $(500 \mu \mathrm{g} / \mathrm{ml})$ treatment reduced the IL-1 $\beta(4.11 \pm 0.32 \mathrm{ng} / \mathrm{ml})$,
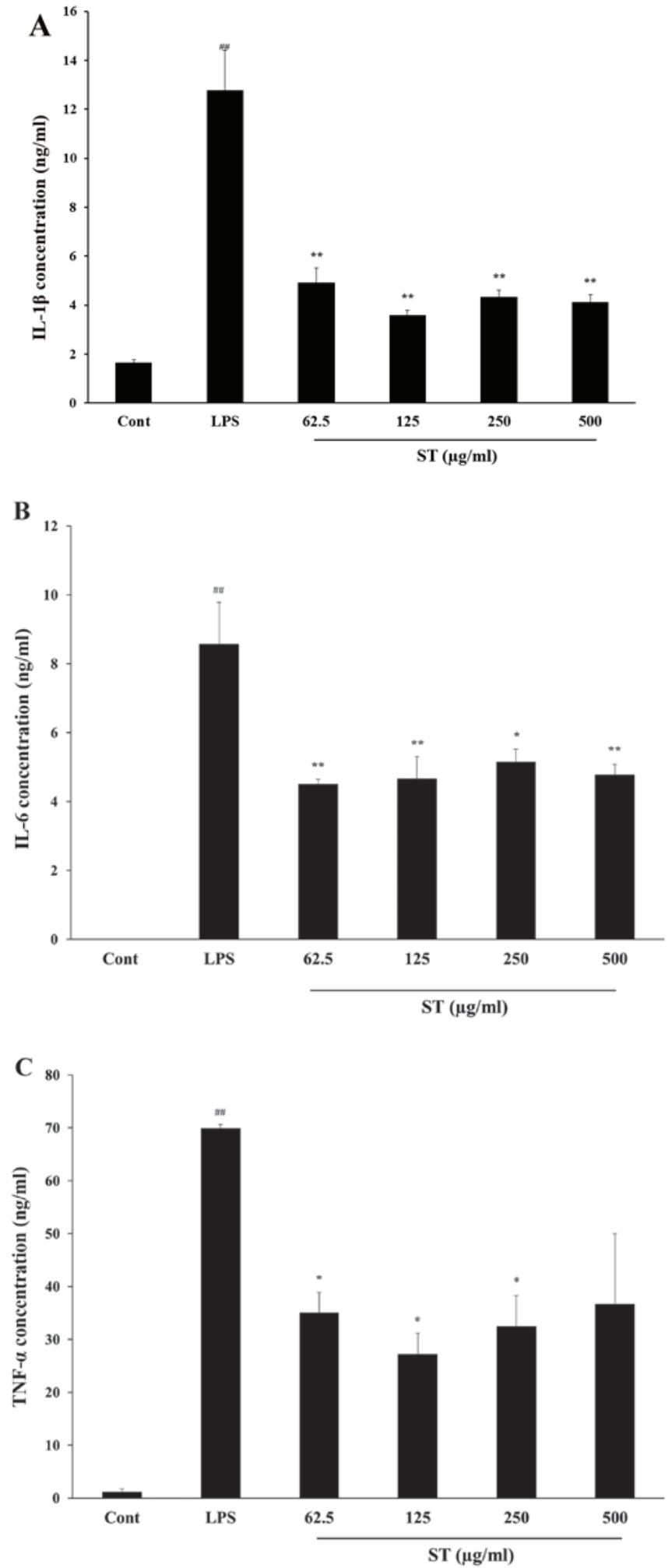

Figure 3. Inhibition of IL-1 $\beta$, IL- 6 and TNF- $\alpha$ by ST in differentiated-THP-1 cells. Cells were treated with various concentrations of ST with LPS $(1 \mu \mathrm{g} / \mathrm{ml})$ for $24 \mathrm{~h}$. (A) IL-1 $\beta$, (B) IL-6 and (C) TNF- $\alpha$ production was inhibited by ST in LPS-stimulated THP- 1 cells. The data are presented as the mean \pm standard error of three independent experiments. ${ }^{\# /} \mathrm{P}<0.01$ vs. cont; ${ }^{*} \mathrm{P}<0.05$, ${ }^{* *} \mathrm{P}<0.01$ vs. LPS. IL-6, interleukin-6; Cont, control; LPS, lipopolysaccharide; ST, Sobokchukeo-Tang; TNF- $\alpha$, tumor necrosis factor- $\alpha$.

IL-6 (4.79 $\pm 0.30 \mathrm{ng} / \mathrm{ml})$ and TNF- $\alpha(36.70 \pm 13.31 \mathrm{ng} / \mathrm{ml})$ released concentrations compared with LPS-only treatment $(\mathrm{P}<0.01$; Fig. 3). Thus, the data confirmed that ST suppressed IL-6 and 

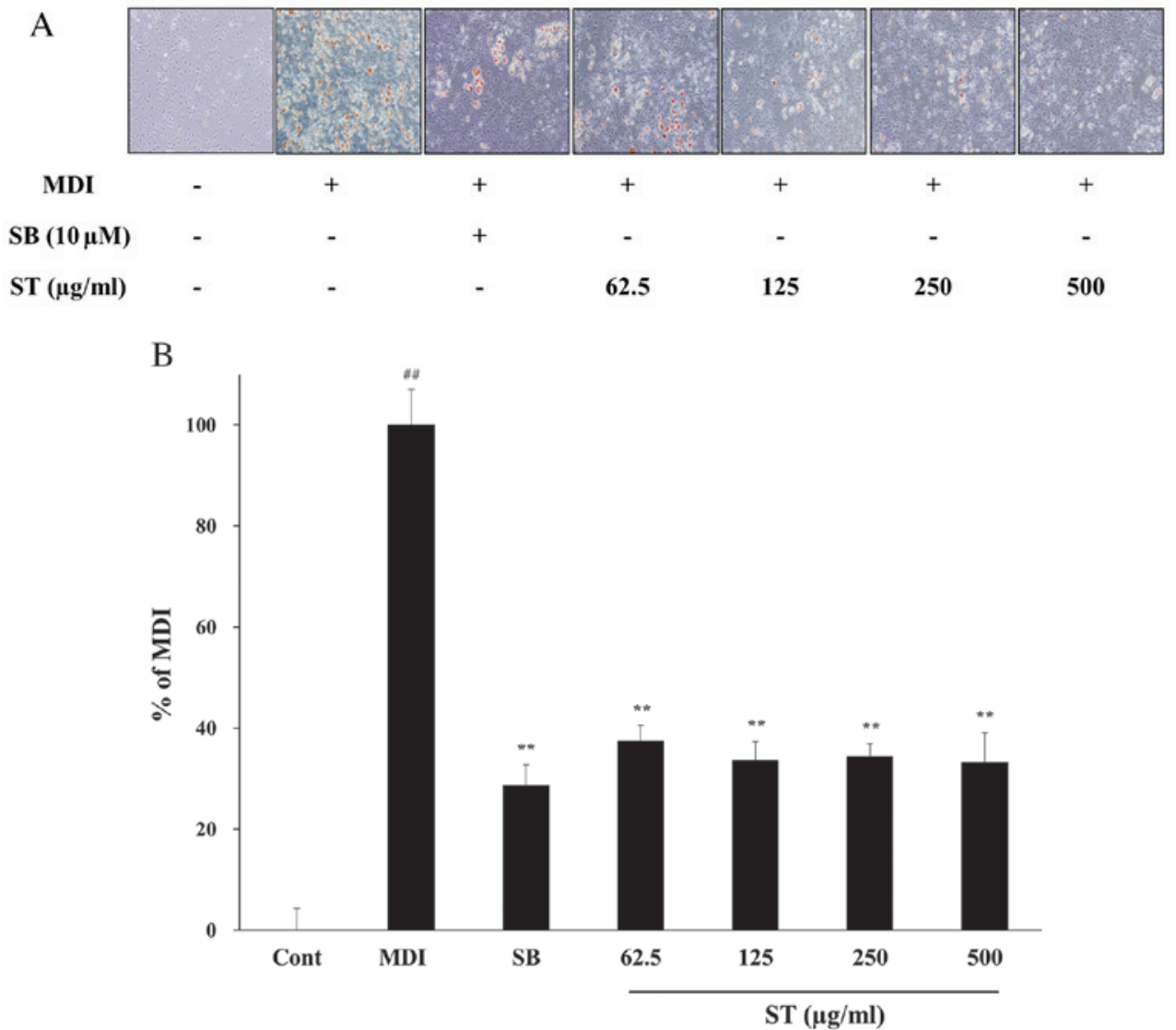

Figure 4. Inhibitory effect of ST on lipid accumulation in MDI-induced 3T3-L1 adipocytes. (A) Fat droplets were measured by Oil Red O staining and observed using microscope (magnification, x100). SB was used as a positive control. (B) Cells were dissolved in DMSO and absorbance (530 nm) was measured to determine lipid accumulation using Oil Red $\mathrm{O}$ dye. The data are presented as the mean \pm standard error of three independent experiments. ${ }^{\# \#} \mathrm{P}<0.01 \mathrm{vs}$. cont; ${ }^{* *} \mathrm{P}<0.01$ vs. MDI. MDI, $1 \mu \mathrm{M}$ dexamethasone, $5 \mathrm{mM}$ 3-isobutyl-1-methylxanthine and $1 \mu \mathrm{g} / \mathrm{ml}$ insulin; SB, SB203580; ST, Sobokchukeo-Tang.

TNF- $\alpha$, anti-inflammatory cytokines, in mouse and human cell lines.

Lipid accumulation in adipocytes. 3T3-L1 cells were incubated in MDI-differentiation medium in the presence or absence of ST extracts. SB203580 treatment was the positive control, and basal growth medium treatment was the negative control. Lipid accumulation was observed by ORO staining on day 7. The retained dye by the fat droplets was dissolved with DMSO and measured at a wavelength of $570 \mathrm{~nm}$ by microplate reader. The fat droplets were increased by MDI-differentiation medium. When SB203580 was administered in the MDI-induced well as a positive control, the fat droplets were inhibited by up to $72 \%$. In the ST treatment group, it was observed that the fat droplets were reduced by ST in a dose-dependent manner (Fig. 4A and B). This suggested that the ST treatment inhibited lipid accumulation and adipogenesis in a dose dependent manner.

Intracellular lipid regulation. The intracellular TG and leptin content was quantified at 7 days post-differentiation of the preadipocytes. The TG content was significantly increased in the cells cultured with MDI by 4-fold $(142.74 \pm 4.14 \mu \mathrm{M})$ compared with the control group $(33.18 \pm 0.89 \mu \mathrm{M} ; \mathrm{P}<0.0001)$. The positive control, SB203580, significantly inhibited TG production in MDI-induced cells compared with MDI treatment alone $(\mathrm{P}=0.003)$. The $\mathrm{ST}$-treated group suppressed the
TG production by up to $50 \%$ compared with MDI treatment only (Fig. 5A).

When 3T3-L1 cells were treated with MDI, the leptin content increased to $156.64 \pm 9.50 \mathrm{pg} / \mathrm{ml}$. In the positive control, the leptin content was significantly inhibited by $\sim 78 \%$ $(34.42 \pm 1.93 \mathrm{pg} / \mathrm{ml} ; \mathrm{P}<0.01$; Fig. 5B), and in the ST-treated group, the leptin concentration was significantly inhibited by up to $95 \%(\mathrm{P}<0.01)$. Thus, $\mathrm{ST}$ suppressed the release of TG and leptin from adipocytes.

Protein expression in adipogenesis. The cell protein levels of PPAR $-\gamma$ and $\mathrm{C} / \mathrm{EBP} \alpha$ were determined. Differentiated cells were treated with various concentrations of ST for 5 days, and the protein levels of PPAR $-\gamma$ and $\mathrm{C} / \mathrm{EBP} \alpha$ were determined by western blotting. As demonstrated in Fig. 5C, SB203580 suppressed PPAR $-\gamma$ and $\mathrm{C} / \mathrm{EBP} \alpha$ expression compared with differentiated cells treated with MDI only. The ST-treated groups exhibited reduced PPAR- $\gamma$ and $\mathrm{C} / \mathrm{EBP} \alpha$ protein levels in a dose-dependent manner. These results indicated that ST inhibits 3T3-L1 pre-adipocyte differentiation partially through PPAR- $\gamma$ and $\mathrm{C} / \mathrm{EBP} \alpha$ via p38 MAPK signaling.

\section{Discussion}

BSS is a blood circulation disorder. Various diseases, including hyperviscosity, ischemic brain injury, microvascular accidents, atherosclerosis, hypertension and pain, are 

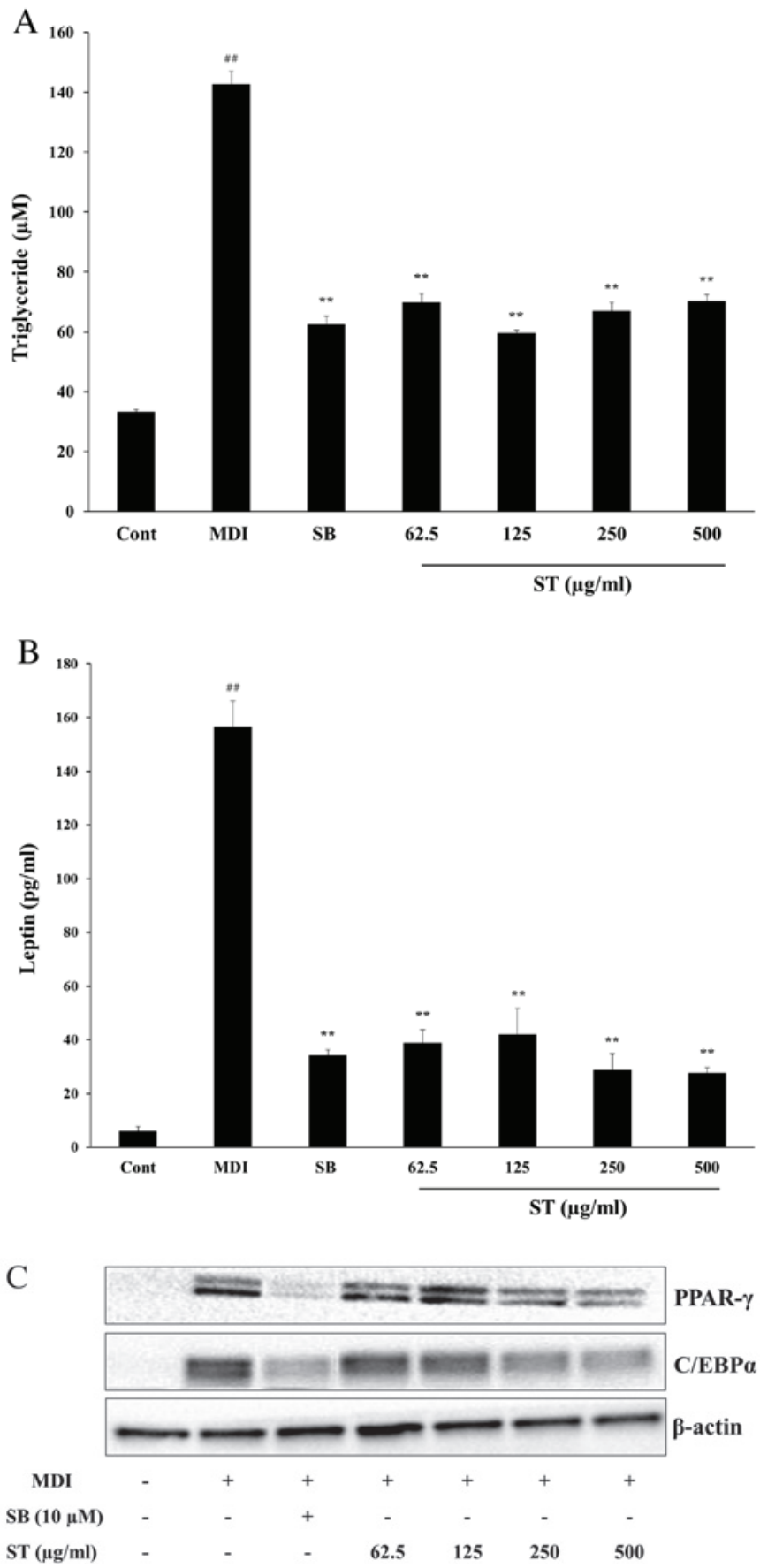

Figure 5. Inhibitory effect of ST on lipogenesis in MDI-induced 3T3-L1 adipocytes. (A) Triglyceride production, (B) leptin production and (C) protein expressions were measured following ST treatment in MDI-induced 3T3-L1 adipocytes. At day 5, protein was isolated from adipocytes and the protein expression levels of PPAR- $\gamma$ and $\mathrm{C} / \mathrm{EBP} \alpha$ were determined by western blot analysis. $\mathrm{T}$ The data are presented as the mean \pm standard error of three independent experiments. ${ }^{\# \#} \mathrm{P}<0.01$ vs. cont; ${ }^{*} \mathrm{P}<0.05,{ }^{* *} \mathrm{P}<0.01$ vs. MDI MDI, $1 \mu \mathrm{M}$ dexamethasone, $5 \mathrm{mM}$ 3-isobutyl-1-methylxanthine and $1 \mu \mathrm{g} / \mathrm{ml}$ insulin; SB, SB203580; ST, Sobokchukeo-Tang; PPAR- $\gamma$, peroxisome prolif-

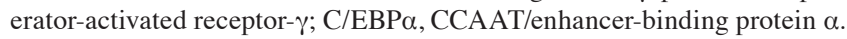

caused by BSS, which can be explained by the inflammatory vascular pathology (20). The traditional herbal formula, ST, is used for the treatment of BSS, pain, cancer and menstrual irregularities. The current study confirmed the efficacy of the anti-inflammatory activity of ST by using adipocytes and macrophages.
Obesity-associated inflammation is suspected to contribute to various diseases, including cancer, cardiovascular disease and diabetes. The proinflammatory cytokines/chemokines, including IL-1 $\beta$, IL- 6 , TNF- $\alpha$, adipokines and leptin, are important for the initiation and development of MDs (21). The present study investigated whether ST modulates the proinflammatory cytokines, IL- 6 and TNF- $\alpha$, and confirmed the cytokine releasing levels in mouse and human macrophage cell lines. ST inhibited the release of proinflammatory cytokines compared with the levels in LPS-treated cells. ST may improve pain and cancer by inhibiting pro-inflammatory activity.

Obesity causes chronic inflammatory reactions associated with pro-inflammatory cytokines (IL-1 $\beta$, IL- 6 and TNF- $\alpha$ ) and adipokines. Numerous studies have indicated that adipocytes produce considerable concentrations of IL-1 $\beta$, IL-6 and TNF- $\alpha$ (22-25). There is a tendency for differentiated adipocytes to undergo apoptosis, followed by macrophage infiltration of the developed adipocytes. Adipose tissue from obese subjects has a higher concentration of secreted cytokines, including IL-1 $\beta$, IL-6, IL-8 and TNF- $\alpha$ (26). Adipose tissue significantly contributes to the production of cytokines. TNF- $\alpha$ is a positively associated with adipocyte size and plasma adipokine levels (27). The current study demonstrated that IL- 6 and TNF- $\alpha$ release is inhibited by ST in a concentration-dependent manner in LPS-treated RAW 264.7 cells and differentiated THP-1 cells, thus, providing another association between fat tissue and inflammation in obesity. Additionally, ST inhibited the production of TG and leptin in 3T3-L1 cells.

Adipocytes are a storage tissue for overnutrition, and it is recognized that adipocytes release numerous factors that regulate inflammation and metabolism. The mechanisms resulting in macrophage development to adipose tissue are currently under investigation. Increased concentrations and release of cytokines and chemokines has been implicated in this process (28). We hypothesize that the reduction in TG accumulation and leptin release following ST treatment is partially mediated by reduced fatty acid synthesis. Leptin serves a crucial role in the endocrine system regarding obesity; it stimulates appetite suppression and regulates energy consumption (29). It is well known that the blood concentration of leptin is closely associated with the TG concentration. The amount of adipose tissue is dependent on circumstances and hormones, including insulin and gonadotropins (30). In the current study, ST inhibited the TG and leptin levels in MDI-induced differentiated 3T3-L1 cells. In addition, ST inhibited adipocyte differentiation and lipid droplet formation.

The expression of the adipogenic markers, PPAR $-\gamma$ and $\mathrm{C} / \mathrm{EBP} \alpha$, were inhibited by ST treatment during adipogenesis of MDI-induced. SB203580 (p38 MAPK inhibitor) was used as a positive control. The role of p38MAPK in adipocyte differentiation remains a controversial topic. p38 activation is altered by MDI-differentiation of 3T3-L1 (31) and suppression of p38 early in MDI-differentiation of 3T3-L1 cells was demonstrated to decrease adipocyte development (32). In the current study, treatment with ST inhibited the PPAR $-\gamma$ and $\mathrm{C} / \mathrm{EBP} \alpha$ expression, which suggested that ST may suppress adipocyte differentiation partially by inhibiting p38 MAPK. It was also observed that SB203580 inhibited PPAR- $\gamma$ and $\mathrm{C} / \mathrm{EBP} \alpha$ expression. 
In conclusion, the results of the current study demonstrated that ST has anti-inflammatory efficacy in LPS-treated macrophages and inhibits adipogenesis in MDI-induced 3T3-L1 adipocytes, as indicated by the significant reduction in TG and leptin accumulation without any cytotoxicity. Furthermore, the suppressive effects of ST are potentially mediated by the downregulated expression of adipogenesis-associated genes. Thus, ST may act as a therapeutic agent to prevent lipid-associated diseases, including obesity and atherosclerosis.

\section{Acknowledgements}

This research was supported by grants from Korea Institute of Oriental Medicine (grant no. K14280).

\section{References}

1. Liu Y, Yin HJ, Shi DZ and Chen KJ: Chinese herb and formulas for promoting blood circulation and removing blood stasis and antiplatelet therapies. Evid Based Complement Alternat Med 2012: 184503, 2012.

2. Jeon BH, Woo WH and Jeong WY: The review of blood stasis concept in oriental medicine. Korean J Oriental Pathology 4: 93-102, 1989.

3. Wang T, Jia C, Chen Y, Li X and Cheng J: Analysis on establishment and affecting factors of qi stagnation and blood stasis rat model. Zhongguo Zhong Yao Za Zhi 37: 1629-1633, 2012 (In Chinese).

4. Lee TC, Lo LC and Wu FC: Traditional Chinese medicine for metabolic syndrome via TCM pattern differentiation: Tongue diagnosis for predictor. Evid Based Complement Alternat Med 2016: 1971295, 2016.

5. Liu X, Guo C, Ma X, Tian R, Zhang Y and Yin H: Relationship between serum estrogen levels and blood stasis syndrome in postmenopausal women with coronary heart disease. Pak J Med Sci 31: 25-30, 2015.

6. Navarro JF and Mora C: Role of inflammation in diabetic complications. Nephrology Dialysis Transplantation 20: 2601-2604, 2005.

7. Jeffcoate WJ, Game F and Cavanagh PR: The role of proinflammatory cytokines in the cause of neuropathic osteoarthropathy (acute Charcot foot) in diabetes. Lancet 366: 2058-2061, 2005.

8. Gunter RN: Blood Stasis: China's classical concept in modern medicine. Elsvier, China, 2006.

9. Zhuo QH, Jiang XF and Zhang YM: Clinical observation of Shaofu zhuyu decoction treating for dysmenorrhea with adolescent functional of 126 cases. Clinical Journal of Experiment Traditional Medicine Formulae 8: 58-59, 2008.

10. Yang SJ and Jin CS: A study on the effects of sobokchukeo-tang on the isolated uterine muscle of rats. J Orient Obestet Gynecol 18: 72-84, 2005

11. Shin WW, Choi JS, Khil JH and Kim SH: Study on antitumor activity of sobokchukeotang and kamisocokchukeotang. J Korean Orient Med 22: 22-30, 2001.

12. Yun YH, Lee DN, Seo IB and Kim HJ: Effects of sobokchukeo-tang on the development of experimentally induced endometriosis in rats. J Orient Obestet Gynecol 19: 141-161, 2006.

13. Cheng YX, Zhou LL, Yan YM, Chen KX and Hou FF: Diabetic nephropathy-related active cyclic peptides from the roots of Brachystemma calycinum. Bioorg Med Chem Lett 21: 7434-7439, 2011.

14. Kern PA, Ranganathan S, Li C, Wood L and Ranganathan G: Adipose tissue tumor necrosis factor and interleukin-6 expression in human obesity and insulin resistance. Am J Physiol Endocrinol Metab 280: E745-E751, 2001.
15. Maachi M, Pieroni L, Bruckert E, Jardel C, Fellahi S, Hainque B, Capeau J and Bastard JP: Systemic low-grade inflammation is related to both circulating and adipose tissue TNFalpha, leptin and IL-6 levels in obese women. Int J Obes Relat Metab Disord 28: 993-997, 2004.

16. Skurk T, Alberti-Huber C, Herder C and Hauner H: Relationship between adipocyte size and adipokine expression and secretion. J Clin Endocrinol Metab 92: 1023-1033, 2007.

17. Yaw HP, Ton SH, Chin HF, Karim MK, Fernando HA and Kadir KA: Modulation of lipid metabolism in glycyrrhizic acid-treated rats fed on a high-calorie diet and exposed to short or long-term stress. Int J Physiol Pathophysiol Pharmacol 7: $61-75,2015$

18. Kota B, Huang TH and Roufogalis BD: An overview on biological mechanisms of PPARs. Pharmacol Res 51: 85-94, 2005.

19. He Q, Huang C, Zhao L, Feng J, Shi Q, Wang D and Wang S: $\alpha$-Naphthoflavone inhibits 3T3-L1 pre-adipocytes differentiation via modulating p38MAPK signaling. Int J Clin Exp Pathol 6: 168-178, 2013.

20. Park B, You S, Jung J, Lee JA, Yun KJ and Lee MS: Korean studies on blood stasis: An overview. Evid Based Complement Alternat Med 3: 2015, 2015.

21. Gokulakrishnan K, Amutha A, Ranjani H, Bibin SY, Balakumar M, Pandey GK, Anjana RM, Ali MK, Narayan KM and Mohan V: Relationship of adipokines and proinflammatory cytokines among asian indian with obesity and youth onset type 2 diabetes. Endocr Pract 21: 1143-1151, 2015.

22. Chang CJ, Jian DY, Lin MW, Zhao JZ, Ho LT, and Juan CC: Evidence in Obese Children: Contribution of hyperlipidemia, obesity-inflammation and insulin sensitivity. PLoS One 10: e0125935, 2015.

23. Akram Z, Abduljabbar T, Abu Hassan MI, Javed F and Vohra F: Cytokine profile in chronic periodontitis patients with and without obesity: A systematic review and meta-analysis. Dis Markers 2016: 4801418, 2016.

24. Basinska K, Marycz K, Śieszek A and Nicpon J: The production and distribution of IL- 6 and TNF-a in subcutaneous adipose tissue and their correlation with serum concentrations in Welsh ponies with equine metabolic syndrome. J Vet Sci 16: 113-120, 2015.

25. Eichelmann F, Schwingshackl L, Fedirko V and Aleksandrova K: Effect of plant-based diets on obesity-related inflammatory profiles: A systematic review and meta-analysis of intervention trials. Obes Rev 17: 1067-1079, 2016

26. Hotamisligil GS, Arner P, Caro JF, Atkinson RL and Spiegelman BM: Increased adipose tissue expression of tumor necrosis factor-alpha in human obesity and insulin resistance. J Clin Invest 95: 2409-2415, 1995.

27. Winkler G, Kiss S, Keszthelyi L, Sápi Z, Ory I, Salamon F, Kovács M, Vargha P, Szekeres O, Speer G, et al: Expression of tumor necrosis factor (TNF)-alpha protein in the subcutaneous and visceral adipose tissue in correlation with adipocyte cell volume, serum TNF-alpha, soluble serum TNF-receptor-2 concentrations and C-peptide level. Eur J Endocrinol 149: $129-135,2003$.

28. Goossens GH and Blaak EE: Adipose tissue dysfunction and impaired metabolic health in human obesity: A matter of oxygen? Front Endocrinol (Lausanne) 6: 55, 2015.

29. Friedman JM and Halaas JL: Leptin and the regulation of body weight in mammals. Nature 395: 763-770, 1998.

30. Pósa A, Szabó R, Kupai K, Csonka A, Szalai Z, Veszelka M, Török S, Daruka L and Varga C: Exercise training and calorie restriction influence the metabolic parameters in ovariectomized female rats. Oxid Med Cell Longev 2015: 787063, 2015.

31. Takenouchi T, Takayama Y and Takezawa T: Co-treatment with dexamethasone and octanoate induces adipogenesis in 3T3-L1 cells. Cell Biol Int 28: 209-216, 2004.

32. Engelman JA, Lisanti MP and Scherer PE: Specific inhibitors of p38 mitogen-activated protein kinase block 3T3-L1 adipogenesis. J Biol Chem 273: 32111-32120, 1988. 